\title{
Inés Echeverría Bello/Héctor Bello: alter ego y escritura feminista chilena en la tercera parte de la serie histórico/ memorialística Alborada (1943-1946)
}

Inés Echeverría Bello/Héctor Bello: alter ego and the feminist Chilean writing in the third part of the historical/memorialistic series, Alborada

(1943-1946)

Montserrat Arre Marfull

Pontificia Universidad Católica de Chile, Santiago, Chile

Contacto: montserrat.arre@uc.cl

https://orcid.org/0000-0002-0156-1358

\begin{abstract}
Resumen
Desde una lectura sociocrítica, el artículo propone la existencia de un alter ego masculino de la autora en un personaje de la tercera parte de la serie de novelas histórico/memorialísticas Alborada, publicadas por Iris (Inés Echeverría Bello) entre 1943-1946, en Chile. A partir de la lectura de las tres novelas que componen esta parte de la serie y las memorias de la autora, publicadas póstumamente, proponemos que Iris se introduce en su narrativa a partir del personaje de "Héctor Bello", el cual cumple las funciones ideológicas que la misma autora cumplía en su espacio político e intelectual en Chile de la década de 1910; sin embargo, no carga con las limitantes impuestas a la mujer de élite. El uso de este alter ego permite a la autora legitimar la discusión de fondo en torno a la crítica social que desarrolla, sin abrir el debate en cuanto a las libertades de las mujeres en el espacio privado de manera tan explícita, y, de esta manera, mantiene una posición relativamente neutral dentro del relato.
\end{abstract}

Palabras clave: Iris; Alter ego; Novela chilena; Sociocrítica; Escritura feminista; Inés Echeverría Bello

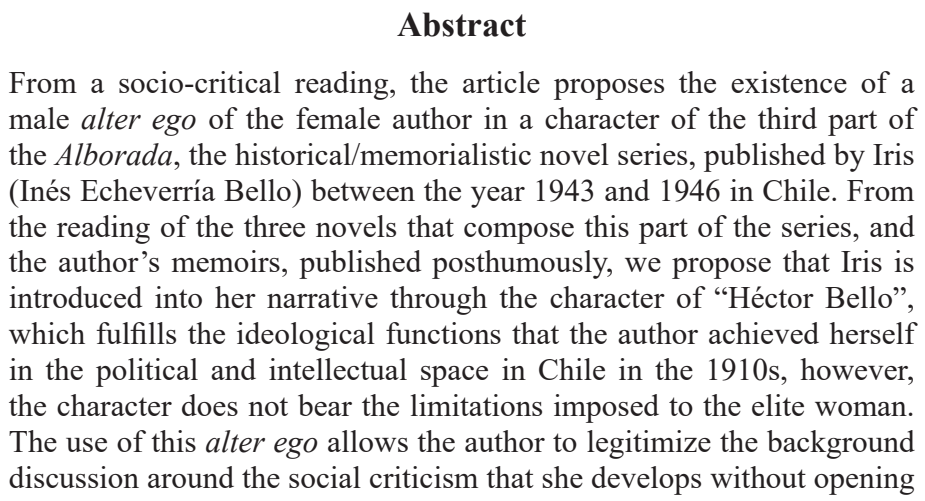


the debate about women's freedom in the private space so explicitly, and, in this way, she keeps a relatively neutral position within the story.

Keywords: Iris; Alter ego; Chilean novel; Sociocriticism; Feminist writing; Inés Echeverría Bello

$$
\text { Recibido: } 11.11 .19 \quad \text { Aceptado: 03.06.20 }
$$

\section{Introducción}

En este artículo expondré una lectura sociocrítica (Prado, 2005) de la tercera parte de la serie de novelas histórico/memorialísticas Alborada, de la escritora chilena Inés Echeverría Bello/Iris, la cual está dividida en tres tomos publicados en 1943, 1945 y 1946 titulados Cuando mi Tierra fue Moza (Arre, 2018; Sánchez, 1976; Subercaseaux, 2000).

La literatura hispanoamericana decimonónica y hasta los primeros años del siglo XX se caracterizó por ser masculina y no especializada, ya que sus autores, en su mayoría hombres, cumplieron también funciones políticas y militares. Entre 1890 y 1920 esta realidad fue paulatinamente variando y se generó, con el paso de los años, un "campo literario" de autores que comenzaron a dedicarse exclusivamente a la literatura, pues tuvieron acceso al mundo universitario en carreras afines y podían, además, llegar a la publicación de sus obras en periódicos y libros con el apoyo de las diversas editoriales que por ese entonces se multiplicaban (Catalán, 1985).

Sin embargo, muchas de las mujeres dedicadas a las letras aún no accedían a la educación universitaria, en muchos casos ni siquiera escolar, y pertenecían, en general, a la clase aristócrata o a la burguesía, cumpliendo paralelamente funciones típicamente femeninas; es decir, ser esposas, madres $\mathrm{y}$, algunas también, señoras anfitrionas de tertulias masculinas. Por lo tanto, se consolidaron, con sus propias variantes, como una continuación de la creación literaria decimonónica no especializada.

Posiblemente, a razón de lo anterior, estas escritoras se expresaron desde una escritura propia y original, alejadas de los moldes académicos pero insertas en las problemáticas sociales y humanas que las aquejaban, lo que las sitúa, tanto en su momento como en un análisis actual, en lo que se ha denominado como escritura de mujeres, escritura femenina o escritura feminista. 
Aquí nos encargaremos de la última definición, pues, si bien las tres etiquetas anteriores no significan lo mismo, necesariamente, se han usado indistintamente en algunos contextos y siempre con un halo inferiorizante. El feminismo (y el feminismo aristocrático) en Chile, particularmente hablando, se ha considerado como una manifestación menor de la narrativa y hasta se lo ha entendido despectivamente como una simple exposición de los mundos oníricos y sentimentales de sus autoras, hasta el punto de posicionarlo como una publicación extensa de diarios íntimos. Sin embargo, al enfocarse en la subjetividad y en el mundo del inconsciente, dicha narrativa poseyó un poder de subversión, eventualmente mucho más peligroso que el presentado en los manifiestos vanguardistas (Poblete y Rivera, 2003, p. 58).

Visto lo anterior, se evidencia que Inés/Iris fue una mujer escritora en un momento de grandes cambios en el campo literario chileno y, además, fue una mujer aristocrática que traspasó diversas barreras para instalarse, junto a mujeres de otras clases, en una vanguardia feminista intelectual que marcó el inicio del feminismo político y social en Chile (Traverso, 2012; Kottow, 2013).

En 1943, Inés/Iris tenía 75 años de edad. Vivió una agitada existencia dentro del mundo de la élite intelectual desde 1904, año de publicación de su primer libro de memorias de viaje titulado Hacia el Oriente. Fue blanco de duros ataques por parte de algunos críticos conservadores por sus siguientes trabajos publicados (memorias de viajes por Europa y sur de Chile, además de novelas cortas y "perfiles y emociones" literarias y teatrales). Estos hombres plasmaron sus prejuicios literarios, religiosos y sexuales en sus comentarios sobre la producción escritural de esta autora. Referente a aquello, sabemos que luego de la censura que hiciera el conservador Pedro Nolasco Cruz sobre la obra de Iris, el interés por esta decayó y las publicaciones posteriores a 1910 quedaron casi desconocidas.

Los acontecimientos narrados en Cuando mi Tierra fue Moza inician con la fundación del Club de Señoras (1915) y el diario La Nación (1917), dos espacios donde se le dio voz a mujeres y hombres progresistas; y finaliza hacia 1920 con la elección como presidente de Arturo Alessandri Palma, candidato populista liberal y promesa de renovación social y política. En esta novela histórica, Inés/Iris transita por el costumbrismo, la crónica periodística, el relato intimista imaginista 
y psicológico, así como por el testimonio, mezclando una variedad de géneros literarios y discursos político-amorosos a través de una diversidad de personajes, en su gran mayoría inspirados en personas reales. Esta transición por diferentes géneros, aunque no siempre bien lograda (Subercaseaux, 2000), era una práctica común de las escritoras de la época, a diferencia del aparato literario masculino donde los roles estaban más claramente establecidos (Alvarado, 2009, p. 51).

A través de Cuando mi Tierra fue Moza, descubriremos a un personaje, Héctor Bello, al cual postulamos como alter ego de la autora y, según nuestra propuesta, está perfilado para construir la legitimación autoral de Inés/Iris en este conflictivo escenario de inicios del siglo XX.

\section{Cuando mi Tierra fue Moza}

Antes de profundizar en el análisis, es preciso mencionar que, si bien la obra que observaremos fue publicada entre 1943 y 1946, la escritura de la misma data de inicios o mediados de la década de 1920. La impresión demorada de esta parte de la serie se relaciona con la publicación tardía de toda la obra, ya que la primera novela de Alborada salió publicada en 1930, siendo que probablemente su escritura había sido comenzada antes de 1910, y la segunda, recién en 1942.

La novela inicia con la fundación del diario La Nación, donde aparece como coagente periodístico el personaje de Héctor Bello, quien era también abogado y escritor. La Nación fue un periódico en el que Inés/Iris colaboró desde el inicio, siendo, además, amiga íntima de su fundador, un influyente político y periodista chileno.

Vemos también que en la novela se transcriben discursos y diálogos probablemente reales dados entre ciertos personajes históricos como, por ejemplo, los discursos realizados por el candidato Alessandri para el Club de Señoras o las conversaciones de Iris, el personaje, con las otras mujeres que participaban en este club en el momento de su gestación y planificación. En dichos pasajes, la realidad vivenciada por la escritora se inmiscuye en su narración y la novela se traslada, en esos capítulos, a la esfera de diario o crónica.

Si bien Iris aparece como personaje en la historia con ese mismo nombre, se establece como rol secundario y se la menciona como sobrina de Teresa Bello, y 
por ende, sobrina del protagonista Héctor Bello, hermano de Teresa en la novela. Iris aparece en los momentos clave de la conformación del Club de Señoras y en algunas escenas con el presidenciable Alessandri. Héctor Bello, por su parte, nunca comparte escena con Iris, y no he podido encontrarlo en la genealogía de la familia Bello, a diferencia de Teresa que sabemos se inspira en una tía real de Inés/Iris, llamada Teresa Prats Bello, conocida por su actividad en pro de la educación femenina.

Héctor es un hombre de 40 años, lleno de dudas y deseos, en crisis existencial durante toda la novela y es quien lleva el peso de la trama principal. Cuando aparece por primera vez, inmediatamente se lo caracteriza en cuanto al linaje, fórmula típica en las novelas de Inés/Iris:

Lleva en su sangre una legión de artistas, idos en plena juventud, que fueron sus progenitores - los Bello- quienes reclaman a Héctor la realización de ensueños, que la muerte frustrara. [...] Por el lado paterno, pertenecía [...] a la aristocracia intelectual y por la línea materna a la nobleza de sangre vasca. (Iris, 1943, pp. 57, 105)

En este punto, y en reiterados momentos cuando la narración refiere características de Héctor Bello, se puede sugerir que Héctor es Inés/Iris. En la realidad, Juan Bello (hijo de Andrés Bello), quien era abuelo de Inés/Iris, escribió cuentos y folletines teatrales en los diarios El Crepúsculo y El Progreso y en la Revista de Santiago, además de traducir del francés textos de Michelet y Seneuill. Murió joven, a los 35 años dejando a dos hijas, Rebeca e Inés. Inés/Iris perdió a su madre a los pocos días de nacer (Inés Bello Reyes) y también presenció, siendo una niña, la enfermedad mental de su tía Rebeca Bello Reyes, quien fuera madre de una sola hija, la famosa Rebeca Matte Bello, primera escultora chilena.

Por otra parte, la referencia a la genealogía del personaje Héctor, por el lado paterno descendiente de la aristocracia intelectual (Bello) y, por el lado, materno de la nobleza vasca, es un claro guiño de Inés/Iris a sí misma, pero al revés: ella desciende de vascos por el lado paterno y de los Bello, por el materno. El único detalle es que en la novela nunca sabemos el segundo apellido de Héctor, solo conocemos que es vasco.

Héctor está ligado a tres mujeres: Elisa Irigoyen, su esposa, madre de sus hijas y con quien vive en la casa Irigoyen Ruiz-Tagle, en el centro de Santiago de 
Chile, junto a su suegra y cuñados. Olivia Smith, casada con uno de los cuñados de Héctor, vive en la misma casa, y es su amante. Y Alba Morgan, amor espiritual de Héctor, ligada a él desde su místico encuentro en viaje por en Tierra Santa; él frecuenta su palacio ubicado en la precordillera de Santiago, donde vive con su esposo, el otro cuñado de Héctor.

Los espacios que cada una de las mujeres ocupan en su relación con Héctor Bello dan cuenta de lo que ellas representan en la evolución intelectual y espiritual del personaje masculino, que podríamos, por una parte, caracterizar como contenedor de la crisis de valores y moral que acontecía dentro de la aristocracia en aquel entonces.

Elisa, su esposa, simboliza la tradición católica española y fanática. Héctor tiene algo de aquello, pues no puede desprenderse de la religiosidad que aún marca su vida, pero ya no desea las amarras del catolicismo español, pues se siente un ser de avanzada. En tal sentido, dicha religiosidad experimentada a su modo no lo amarra a los convencionalismos sociales en tanto ordenamiento moral. Casado y con hijas, no siente remordimiento de su infidelidad y solo se cuestiona su actitud en el momento en que entiende que la relación con su amante no es emocionalmente satisfactoria.

Olivia, la amante, simboliza la nueva aristocracia que aparece a fines del siglo XIX, como se describe en la novela: "[A] la aristocracia del nombre y de la hacienda, se unió la aristocracia del talento y la política. Sólo después de la guerra con Perú, vino la aristocracia del dinero" (Iris, 1943, p. 309).

Apellidos extranjeros llegan a irrumpir a las clases altas con su avasalladora modernidad, no siempre bienvenida. Héctor se desliga poco a poco de Olivia, ya que, además de las diferencias espirituales están sus diferencias de linaje. Esa es la distancia que finalmente se constituye entre ambos: ella moderna en el sentido superfluo de la palabra, vale decir, vive su liberalidad, guardando las formas sociales externas; mientras, él es moderno en el sentido espiritual, por su deseo de estar a la vanguardia del despertar de las conciencias.

Singularmente son, en este esquema, dos de las tres mujeres señaladas las que se quedan atrás y no avanzan con el advenimiento de la Nueva Era (la 
Alborada), mientras el hombre de estirpe Bello, foco de la acción, es quien se mueve y descorre los velos para encontrar la verdad.

Finalmente, Alba Morgan es el símbolo del amor que evoca la autora en los prólogos de sus novelas. El amor es el concepto clave de esta historia. No el amor que pretende la regla social, mediante el matrimonio, ni tampoco el amor físico. Es el amor que se constituye de espíritu e intelectualidad, o de teología y ciencia, siguiendo las doctrinas de la Teosofía que marcan el devenir de Inés/ Iris y su narrativa. Durante toda la novela, se insiste en que Héctor está llamado a la creación de una gran obra, pero es incomprendido por la sociedad. Su raza y sus ancestros le han prescrito el camino. Gracias a Alba, es decir, al amor, podrá encausar esa fuerza vital que lo inunda.

\section{3. ¿Alter ego?}

Inés/Iris muestra, a través de su literatura, que la mujer aristocrática es, en su época, el sujeto llamado para guiar y enriquecer, a través de sus capacidades espirituales y fuerza moral, el devenir intelectual y político de la Patria (Echeverría, 2005, p. 537; Traverso, 2012), y así perfeccionar la acción de hombres educados de clases media y alta. Es lo que repite en sus capítulos testimoniales y lo que se interpreta a través de sus escenas alegóricas en la novela.

Alba es la mujer que literalmente ilumina este camino hacia la Alborada, que es el momento de cambio social y espiritual; no obstante, Héctor, un hombre, es quien representa el nudo de conflicto, situado en una particular aristocracia intelectual. A pesar de que hay algunos personajes claramente representantes del pensamiento de la autora y otros que se establecen como los antagonistas de dicho pensamiento en esta novela, cada uno de ellos ocupa un lugar en la historia estableciéndose en puntos invariables: Elisa conservadora, Olivia hedonista, Alba espiritual, por ejemplo. Solo Héctor sufre dudas, deseos, aspiraciones de cambio.

El conflicto de Héctor, si bien representa la crisis de la aristocracia y la transformación de la intelectualidad de la época, también es representativo de la autora y de sus propios cuestionamientos y experiencias. En la escritura de mujeres, en el cambio de siglo y en su autoconcepción como escritoras, la figura masculina suele tener un papel central, al ser esta el único referente de la 
intelectualidad hasta ese momento. De tal manera, se puede decir que los orígenes de la autora-creadora se hallan en la anomalía del género, en la diferenciación que constituyen estas escritoras con las otras mujeres de la familia y en la identificación con la figura masculina (Traverso, 2012, p. 75).

Héctor representa la expresión de la nueva intelectualidad, siendo periodista en La Nación, y no obstante ser un autor difundido, aunque criticado por sus ataques a la aristocracia tradicional, no es un escritor completo, pues debe ejercer de abogado para vivir, y vive, además, en un hogar donde se lo reprime y critica. Héctor Bello es un héroe rebatido por conservadores y católicos, pero acusado de beato por los radicales a causa de su espiritualismo, es decir, se instala en el mundo novelístico más o menos en la posición que Inés/Iris ocupaba en el Santiago de entonces (Prado, 2005, p. 155). Si nos aventuramos por esta senda, tomando en consideración lo ya referido, es congruente afirmar que Héctor es el alter ego de la autora.

Sin embargo, es preciso preguntarnos: si Héctor es Inés/Iris, ¿por qué es hombre, siendo que la autora era una abanderada de la mujer y sus potencialidades, era una feminista? Mostraremos algunas de las citas de la novela donde se puede apreciar este símil, para justificar nuestra hipótesis y dar algunas respuestas a estas interrogantes.

Se cuenta que Héctor lleva un diario personal y que ha publicado ya un libro, el cual habría sido recibido positivamente por artistas e intelectuales pero criticado por el clero y la más rancia aristocracia. Nunca se indica qué tipo de libro es, pero podría ser una alusión a la crítica que se ha hecho a Inés/Iris hacia 1910 y sus publicaciones. Se lee en la novela, además, que Héctor "está colocado a la vanguardia evolutiva del país, pero ¡cuán solitario y herido se halla!” (Iris, 1943, p. 111).

Preciso es aludir a las Memorias de Iris, 1899 a 1925 publicadas recién en el siglo XXI, donde leemos unas líneas que la autora escribió hacia 1920, al rememorar su viaje a Roma en 1901 y sus años escribiendo en La Nación:

Mis amigos me llamarán despectivamente apóstata y para los eclesiásticos seré un azote. Creen que los ataco por malevolencia y malsana ironía [...] ¡Error! Llevo un anhelo íntimo de restauración 
cristiana. [...] Durante mis [...] años de periodismo en La Nación, trato que despierte [la mujer], por creer que es ella la llamada a devolver la luz que ha perdido el mundo. Nadie me comprende, lucho sola. (Echeverría, 2005, p. 95)

También es relevante la mención de la genealogía de Héctor, a la cual ya se ha aludido, indicándose que, por parte de la madre, desciende de la nobleza de sangre vasca y, por lado paterno, de la aristocracia intelectual. Héctor lleva como primer apellido el de Bello; según cuenta la novela, “Andrés Bello, codificador del continente americano, transmitió a sus descendientes una naturaleza propensa a la tuberculosis, temperamento pasional y talento artístico" (Iris, 1943, p. 105). Siendo las últimas dos características particularidades de nuestro personaje y, sin duda de Inés/Iris según sus propias palabras, quien, en la realidad, era bisnieta del famoso intelectual latinoamericano. Es reiterativo en la novela este nexo familiar, que instala a Héctor en una posición aventajada y necesaria en el camino de la “evolución espiritual” de Chile.

En sus diversas críticas de tono anticlerical, Héctor desliza la idea de que, estando en medio de una era de renovación espiritual y de cambio social, los conflictos de las clases deben solucionarse por "vía teosófica", que es la unión, según lo explica, entre la religión y la ciencia. En una conversación de Héctor con su amigo fundador del periódico, a propósito de Europa y refiriendo su función en La Nación, cuenta:

Nunca estuve en un rincón de montaña sin encontrar teosofistas, ni subí en un tren o me senté en una mesa de restaurant... Invadían el planeta. Aquí no les dan importancia porque no los entienden. [...] Si al levantar esta antorcha que es el Espiritualismo trascendental, en la tiniebla, hemos conseguido iluminar las partes oscuras de la llanura evolutiva, nuestra obra será grande. (Iris, 1943, p. 146)

Sabemos que Inés/Iris pasó varios años en diversos países de Europa y en Tierra Santa, en viajes entre los cuales regresaba a Chile. En ellos conoció una nueva forma de religiosidad y comenzó a relacionarse, además, con el arte y escritura de una manera distinta. Sus memorias de estos viajes son archivos vivientes del proceso de abandono del universo doméstico y patriarcal y, de alguna manera, la entrada desautorizada y con bastante comodidad al secular mundo de distintas culturas en restaurantes, trenes, museos y calles (Prado, 2005, pp. 73-76). 
En otro ámbito, y de una manera muy esclarecedora para nuestra propuesta, relacionado además con lo señalado por Inés/Iris en sus Memorias mencionado más arriba, Héctor Bello dice, a propósito de La Nación:

Queda entendido que en el Diario yo ocuparé la Torre - avizor de lontananzas, marcaré las horas y anunciaré la Alborada... ¡Eso me gusta!... Las almas que están en vela, me escucharán... Han de ser escasas... El sueño de la siesta colonial, es pesado en esta tierra silenciosa. (Iris, 1943, p. 142)

Inés/Iris, así como su personaje Héctor, se siente una persona aventajada. Se perfila a sí misma como testigo reflexivo de un cambio de siglo y de un nuevo futuro social y espiritual y, a la vez, como protagonista de este cambio. Lo leemos en sus prólogos a la obra Alborada y en diversos artículos periodísticos, muchos de ellos publicados en La Nación, y también en sus Memorias:

Me hallo en una isla solitaria. En la torre de mi templo interior estoy enteramente solitaria... Mi familia ha bajado al sótano y se ha confinado en su sombra helada... Todos los seres que traen una misión de avanzada en la tierra necesitan blandura de nido... Mi marido se siente vejado por mis ideas... Cada artículo mío le quema el rostro. (Echeverría, 2005, p. 515)

Otro aspecto en el cual podríamos relacionar a Héctor con la autora se observa en la siguiente escena. Un día, al llegar Héctor Bello a casa de su amigo (hermano de Alba), hablan sobre los alcances del conocimiento oriental y,

Ya en la subida de la escalera Alfredo [Morgan] preguntó con ironía: - ¿Y la polémica con don Pedro Nolasco? Era un notario que hacía críticas de arte, en estilo de actas oficinescas. La pregunta entrañaba la burla, pues a Morgan parecían sainetones aquellos artículos de prensa, en que un espíritu tan ágil como el de Bello había de medirse con el peso de una lenta carrera colonial. - Ya no da lecciones de gramática; se ha resignado a ser un clásico y un castizo, sin talento, ni ideas y lo que es peor, sin imitadores. (Iris, 1943, pp. 243-244)

Esta escena es muy señera, pues luego de las reflexiones de los personajes Morgan y Bello acerca del conocimiento oriental, mencionan este conflicto dado en el medio literario entre Héctor y Pedro Nolasco, el mismo que Inés/Iris sufrió en su vida literaria con este crítico. Tal conflicto es señalado en otras ocasiones, por lo tanto es un hecho recurrente en la vida de Bello que aspira a esparcir su 
mensaje artístico y espiritual (Iris, 1946, pp. 38-39). Si bien es sabido que Pedro Nolasco Cruz fue un crítico que solía ser lapidario con muchos escritores y obras que no obedecían a una moral más bien conservadora, particularmente el episodio de crítica en la vida literaria y pública de Inés/Iris se escenifica ficcionalmente en la experiencia de Héctor (Prado, 2005, p. 159).

Finalmente, una escena relevante sobre esta identificación entre Inés/ Iris y Héctor Bello es la que acontece tras uno de los últimos encuentros entre su amante y él, cuando vuelve a su oficina lleno de angustia. Entrando en la psiquis del personaje, se describe su estado de ánimo y sus pensamientos:

Germina en su mente el plan de una "Obra" de renovación social y trasmutación de valores, aumentando su intuición [...]. Su cerebro ha sido fecundado y se halla en trance de preñez, desproporcionada a sus fuerzas y cuyo feliz alumbramiento requiere paz interior, a que su turbada vida profesional y sentimental, no se presta. El periodismo también le ha creado un público que lo tiraniza. De sus escritos brotan chispazos de luz que han logrado despertar a muchas almas del sueño colonial de la raza. (Iris, 1943, p. 305)

Luego de esta introspección, Héctor piensa en su familia. Ya casi no habla con Elisa, pero le preocupan sus hijas, las cuales deberán prontamente entrar en sociedad. Tenemos aquí una visión femenina del trance de transformación. Primero que nada, aludir a una simbología maternal para definir el acto de renovación mental de Héctor deviene de una visión de una mujer que ha sido madre, y ha experimentado la fecundación y la preñez en carne propia, tanto de manera física como intelectual. Es necesario aludir a las Memorias en este punto y el símil que realiza entre la publicación de Hacia el Oriente como un acto de haber parido un hijo "ilegítimo" y, paralelamente, el nacimiento de su cuarta y última hija. Por otra parte, esa preocupación por las hijas, tiene también un correlato en la realidad de Inés/Iris: ella rompe con la aristocracia más conservadora en su vida real, incluso entra en conflicto con su propio marido e hijas (Echeverría, 2005, pp. 515-521), lo que simboliza Elisa y su familia en la vida de Héctor, aunque este último no desea enajenar a sus hijas del trato social. En sus memorias, Iris escribe (muy en consonancia con Héctor):

Hay en mí una curiosidad y egoísmo desenfrenado. Probablemente también el erotismo se emboza de romanticismo. Con el siglo XIX 
ha terminado la mujer niña y voy a entrar al fuego del combate. [...] Buscaba amor humano, ahora lo quiero espiritual. Deseaba hacer novelas que fijasen y exaltasen esta belleza de la vida terrenal, y ahora quiero hacer una obra de arte trascendental. (Echeverría, 2005, p. 92)

Ahora bien, volvamos sobre la pregunta: si Héctor es Inés/Iris, ¿por qué la autora elige a un hombre para representarla? ¿Por qué no sería Iris, como el personaje que sí aparece en la novela, la mujer que representa la complejidad de la experiencia de la autora? Primero que nada, Iris personaje aparece solo en ámbitos públicos y nunca se indaga en sus reflexiones internas ni tampoco se la muestra en un conflicto existencial. Como personaje, es una mujer que escribe con ideas feministas, que apoya al candidato Alessandri, colabora en el Club de Señoras y admira a su marido. No es un personaje que cambie ni evolucione, representa un estado de cosas, un pensamiento, un personaje tipo de un momento histórico específico.

Sin embargo, la autora, si la seguimos en su amplia obra, es una escritora que tiene una particular forma de pensamiento, caracterizado a grandes rasgos dentro del "espiritualismo de vanguardia" y el "feminismo aristocrático", así definidos por Bernardo Subercaseaux; su propuesta va "evolucionando" a medida que va experimentado un aprendizaje intelectual y espiritual, a medida que, literalmente, vive, sufre y envejece. Esa transformación es Héctor.

Propongo que Inés/Iris se representó a sí misma en un hombre, pues los cuestionamientos internos y las posturas propias que se oponen a la moral tradicional católica podrían haber sido menos cuestionables en un personaje masculino. Un hombre tenía todo el derecho social de ser infiel a su esposa y hasta despreciarla, por ejemplo, lo que para una mujer era impensable, sin caer en el descrédito social. Olivia es infiel, no se cuestiona su infidelidad directamente, pero sufre las consecuencias finales de sus acciones, termina desechada por sus amantes y adicta a la morfina (Iris, 1946, p. 278). En tal sentido, Inés/Iris continúa, contradictoriamente, con el presupuesto patriarcal, pues no lo rebate en Héctor. Le permite engañar a su esposa, sin culpa ni carga emocional o social.

Por otra parte, el nexo entre las relaciones amorosas y emocionales y la constitución de lo social público, la política y la intelectualidad, es un continuo 
que guía la obra Alborada (Prado, 2005, p. 127) y, asimismo, la existencia de la autora. En su vida pública su apelación a la emotividad y sensibilidad "propia" de la mujer, lograba justificar la opinión o producción escritural femenina, distanciándola de la masculina.

De alguna manera, la metáfora de las imposibilidades amorosas de Héctor Bello, son las imposibilidades experimentadas por las mujeres en el ámbito público. La historia de las mujeres es la historia de la negación y de la imposición social. Igualmente, la historia de Héctor y sus amores fallidos, con tres opciones dadas: aceptación social, amor físico y amor espiritual, es la historia de las imposiciones y las negaciones.

Héctor debe ser un marido que siga la normalidad del espacio conservador en donde habita, ser abogado y político (conservador) es lo esperable para él; puede permitirse una infidelidad, no es improbable ni imposible, pero la familia debe mantenerse, no puede pretender enamorarse de la querida, solo es una entretención, así lo entiende la misma Olivia, de alguna manera más masculina en su postura desinhibida. Luego, como Héctor no apuesta a la norma social (falsa) sino a la verdadera vocación, se debate entre el amor a su descendencia (hijas) y el nuevo retoño que nacerá, ya no de su cuerpo sino de su mente y alma.

\section{Conclusión}

El conflicto representado a través del personaje de Héctor Bello es simbólico de lo que vivían las señoras/intelectuales de la época que, si bien se convirtieron en escritoras, fueron ante todo madres y esposas, que debían cumplir con una serie de obligaciones propias de su rol asignado en la sociedad (Traverso, 2012, pp. 67-68), y particularmente representativo de la situación histórica y concreta de Inés/Iris, como mujer situada dentro de la vanguardia intelectual de inicios del siglo XX.

Hemos propuesto en al artículo que Inés/Iris se esconde tras Héctor, pues solo ahí es libre de criticar a su cónyuge, hijas y familia cercana sin apuntarlos directamente. Cuando Iris aparece como personaje, se la refiere como mujer casada con un "gran señor", un hombre respetable y respetado; así lo indica la narración. La mirada hacia su marido es positiva, y nada se menciona sobre las 
diferencias ideológicas con su esposa. No obstante, según las Memorias de Inés/ Iris, sabemos que antes de 1910 ya comenzaba, poco a poco, el resquebrajamiento ideológico y emocional del matrimonio entre Inés Echeverría Bello y Joaquín Larraín Alcalde, el que nunca se pudo recomponer.

Esa separación entre Héctor y Elisa es absoluta hacia el final del tomo III de Cuando mi Tierra fue Moza; así, el protagonista masculino solo es redimido por la iluminación espiritual de Alba, que lo llevará a un nivel superior de conciencia. De esta manera, el uso del alter ego permite a la autora legitimar y realzar la discusión de fondo en torno a la crítica social que desarrolla Alborada. Ello sin abrir el debate en cuanto las libertades de las mujeres, y de ella en particular en el espacio privado de manera tan explícita; así puede mantener una posición relativamente neutral dentro del relato, que le permite proteger la identidad de su propia familia y reservar para sí sus propios conflictos personales, como esposa, madre y mujer intelectual.

\section{Agradecimientos}

Este artículo forma parte de la investigación doctoral en Ciencias Humanas y Estudios Comparados presentada en 2018, realizada en cotutela entre la Universidad Austral de Chile (UACh) y la Universidad de Lisboa (ULisboa). Agradezco a las profesoras Ana Traverso Münnich (UACh), Ángela Fernandes (ULisboa) y Lorena Amaro (PUCCh), por sus aportes sustanciales durante el desarrollo de la investigación, y a la Comisión Nacional de Investigación Científica y Tecnológica (CONICYT) por el financiamiento a través de la Beca para Doctorado en Chile 2014-2018. Un avance de este artículo fue presentado en Primer Congreso Internacional de Investigación y Crítica sobre Literatura Española (CICLE), Universidad de Extremadura, Cáceres, España, 10 y 11 de noviembre de 2016.

\section{Notas}

1 Eran más bien autodidactas; algunas fueron educadas con institutrices y otras se desarrollaron buscando espacios donde instruirse con amistades y familiares.

2 Es preciso puntualizar que cuando Iris comienza a publicar Alborada, es el 
momento de consolidación del campo literario chileno; esto principalmente a través de la producción novelística del criollismo, además de la aparición de algunas vanguardias literarias o ismos, etapa que se señala como posterior a un período de transición datado por la historia literaria entre 1890 y 1920, que converge hacia la especialización profesional. Sin embargo, ello es posible observarlo preferentemente en la tradición masculina.

3 Lo que implica imaginar esta escritura como algo menos elaborado o pensado, y simplemente como algo instintivo.

4 Según Marcela Prado Traverso, es precisamente desde 1910 donde podemos encontrar la mejor expresión de la obra de la autora (2005, pp. 166-167).

5 Otro crítico de gran peso, Alone (Hernán Díaz Arrieta), publicó un artículo 1943 donde se lamentaba que, habiendo sido Chile en el siglo XIX fuente de excelentes retratos literarios inspirados en la alta sociedad, el siglo XX casi diera solo literatos que gustaban retratar el mundo popular, existiendo, según su opinión, tanto potencial en escribir sobre las clases aristocráticas. Dice el crítico que "son relativamente pocas en el mundo literario las novelas que traducen exactamente la fisonomía de la clase social aristocrática. Se requiere para ello condiciones raras: desde luego, la más rara de todas, la intuición psicológica, la penetración de los matices diferenciales en el carácter" (Alone, 1943 , p. 242). El autor enumera en el artículo una lista de a lo menos 20 escritores chilenos destacados desde 1900 hasta esa fecha; no obstante, mujeres solo nombra a Gabriela Mistral, la que no es de la élite ni tampoco novelista. Curioso, cuando para aquella fecha, Iris había ya publicado 11 libros, entre ellos novelas, y en todos ellos su perspectiva de narración se posicionaba desde la clase alta, de donde ella provenía, y sus análisis penetraban en las costumbres y psicología de su clase.

6 Bernardo Subercaseaux (2000) define Alborada como un "híbrido narrativo", una "novela monstruo".

7 En las Memorias de Iris, Inés/Iris escribe en 1923: "Cuántos outsiders en el mundo. Todos los que carecen de sentido práctico, los idealistas, los sentimentales, los espiritualistas y los verdaderos cristianos. Debo hacer a mi personaje Héctor Bello algo outsider para que exprese mis ideas. Outsiders son los héroes, los santos, todos los que llevan en la vida mezquina y limitada del mundo un ideal superior..." (Echeverría, 2005, p. 477).

8 Aludiré a Iris, cuando sea personaje, y a Inés/Iris, cuando refiera a la autora.

9 Teresa Prats Bello era nieta de Andrés Bello, y tía de Inés Echeverría Bello aunque solo pocos años mayor que esta última. Murió tempranamente en 1914, a los 49 años. Hasta lo que sabemos, no tenía ningún hermano llamado 
Héctor. Según Subercaseaux (2000, p. 99), Héctor Bello representa al conocido escritor Joaquín Edwards Bello en la novela. Sin embargo, diferimos de esta propuesta puesto que, si bien podrían haber algunos elementos que identifiquen rasgos de Edwards Bello en Héctor Bello (crítica a la aristocracia, agudo cronista en La Nación, ciertas características físicas), hay muchos más elementos que lo ligan a la propia figura de Iris en su medio social. De partida, la postura religiosa del personaje Héctor Bello es la misma que tiene Iris: él también es teósofo y a la vez católico y, hasta lo que sabemos, Edwards Bello no era religioso.

10 Esta novela, puede seguirse a través de varias tramas que se entrelazan, tramas que convergen o transitan por dos personajes femeninos principales: las hermanas Luz y Alba Morgan Lynch. Ambas mujeres de la élite están ligadas a dos personajes masculinos protagonistas: Juan García, joven músico y dirigente estudiantil de vida precaria y Héctor Bello, un abogado de familia ilustre pero venida a menos. Luz y Alba son personajes inspirados en las hermanas Carmen y Ximena Morla Lynch respectivamente, hijas de Luisa Lynch Solar y su tío Carlos Morla Vicuña (Carlos Vicuña Zaldívar); quienes fueron conocidas por sus sesiones de espiritismo a inicios del siglo XX.

11 Referencia a la Guerra del Pacífico entre Bolivia y Perú contra Chile (18791883).

12 Especialmente, en su libro Hacia el Oriente, Iris está pasando por una profunda crisis de identidad, en donde el elemento religioso es esencial, tanto por su crítica anticlerical como por su interpretación libre del evangelio y el conocimiento de las vertientes espiritualistas de Oriente que va acogiendo.

13 Pedro Nolasco Cruz comenzó sus publicaciones en 1882; escribió artículos de censura de las costumbres, divulgación de letras, novelas y cuentos, pero desde 1889 se dedicó exclusivamente a publicar crítica literaria. En 1903 fue nombrado subsecretario del Ministerio de Guerra y Marina y desde 1913 comenzó a ejercer de notario público en Santiago. "Aun cuando por la franqueza de sus opiniones críticas no pocos de [sus] estudios le valieron duros ataques, jamás salió en defensa de sus escritos ni parecía darse por advertido de la reacción que ellos provocaban” (Silva, 1969, p. 19).

14 "Por cuarta vez mis sufrimientos se inutilizaban sin obtener el hijo varón, tan deseado por ambos. [...] No le hice la cuna o me atrasé... nunca se está preparada para alumbrar gemelos, y habiendo dado a luz a mi primogénito, Hacia el Oriente, lanzado al mundo huérfano sin nombre, debía preocuparme más de ayudar a que respirase bien en el aire humano. [...] Mi hijo espurio, según el mundo, me daba más cuidado que el otro pequeño ser de bien conocida ascendencia, que tenía su hueco pronto en el mundo y que después de darnos 
gran chasco sería el ser mimado de todos, como lo era yo misma" (Echeverría, 2005, p. 239).

15 Sabemos, por las diversas fuentes de la época y las propias memorias de Iris, que ella tuvo varios enamorados, aunque nunca se separó de su marido; estos amoríos causaron habladurías constantes. Según las Memorias, su gran pilar de vida fue su marido Joaquín Larraín, con quien, sin embargo, comenzó una separación emocional e ideológica después de 1905, agudizada hacia 1919 durante la candidatura de Alessandri. Por esa misma época aparecieron en su vida tres hombres (escritores) que dijeron estar enamorados de ella: Luis Orrego Luco, Fernando Santiván y Eliodoro Yáñez, pero es Yáñez en quien Iris repara constantemente en sus Memorias, y de quien declara haberse enamorado profundamente. También se la ligó sentimentalmente a Arturo Alessandri, pero más allá de su admiración declarada, no se sabe; por lo menos ella no lo declara, que haya sido otro de sus amores. Aunque también manifiesta en sus Memorias, que todos estos amores nunca llegaron a tener consumación física.

\section{Referencias bibliográficas}

Alone [Diaz Arrieta, H.]. (1943). La alta sociedad y la Literatura en Chile. Atenea, 219 (73), 234-250.

Alvarado Cornejo, M. (2009). Contra-tradición: prácticas críticas y desestabilizadoras de escritoras chilenas de principios del siglo XX. Ogigia. Revista Electrónica de Estudios Hispánicos, 5, 41-51. https:// dialnet.unirioja.es/servlet/articulo?codigo $=2800816$.

Arre Marfull, M. (2018). La raza en la literatura: Alborada de Iris y la retórica de la modernidad en una escritora de Vanguardia (Tesis para optar al grado de Doctora en Ciencias Humanas/Estudios Comparados). Universidad Austral de Chile, Universidad de Lisboa.

Catalán, G. (1985). Antecedentes sobre la transformación del campo literario en Chile entre 1890-1920. En J. J. Bruner y G. Catalán (Eds.), Cinco estudios sobre cultura y sociedad (pp. 69-175). Santiago: Facultad Latinoamericana de Ciencias Sociales.

Echeverría Bello, I. (2005). Memorias de Iris. 1899-1925. Santiago: Aguilar. 
Iris. (1943). Cuando mi Tierra fue Moza. Tomo I: Amanecer. Santiago: Nascimento.

Iris. (1946). Cuando mi Tierra fue Moza. Tomo III: Umbrales del futuro. Santiago: Nascimento.

Kottow, A. (2013). Feminismo y femineidad: escritura y género en las primeras escritoras feministas en Chile. Atenea, 508, 151-169. https://doi. org/10.4067/S0718-04622013000200011

Poblete Alday, P. y Rivera Aravena, C. (2003). El feminismo aristocrático: violencia simbólica y ruptura soterrada a comienzos del siglo XX. Revista de Historia Social y de las Mentalidades, 7, 57-79. http://www.revistas. usach.cl/ojs/index.php/historiasocial/article/viewFile/329/324

Prado Traverso, M. (2005). Escritoras chilenas de la transición. Siglo XIX-XX. Valparaíso: Universidad de Playa Ancha.

Sánchez, L. A. (1976). Proceso y contenido de la Novela Hispano-Americana. Madrid: Editorial Gredos.

Silva Castro, R. (1969). Estudio Preliminar. En La Literatura Crítica de Chile (pp. 9-44). Santiago: Andrés Bello.

Subercaseaux, B. (2000). Las mujeres también escriben malas novelas (sujeto escindido e híbrido narrativo). Revista Chilena de Literatura, 56, 93-103. Recuperado de: https://revistaliteratura.uchile.cl/index.php/RCL/article/ view/39202.

Traverso Münnich, A. (2012). Primeras escritoras en Chile y autorización del oficio literario. Anales de Literatura Chilena, 17 (13), 61-80. https:// dialnet.unirioja.es/servlet/articulo?codigo $=4245398$. 